\title{
Treatment of Leachate by Electrochemical Oxidation using Graphite and Titanium Electrodes
}

Pavithra MP*1 and Pushpa Lumina ${ }^{2}$

1.* Assistant Professor,Department of Civil, REVA University, Bengaluru, India.

2. Assistant professor,Department of Civil, REVA University, Bengaluru, India.

\section{Publication Info}

Article history :

Received : 30 $0^{\text {th }}$ June, 2019

Accepted : $5^{\text {th }}$ Dec, 2019

DOI : $10.18090 /$ samriddhi.v11i02.4

Keywords :

Landfill leachate, Graphite, Titanium Electrochemical oxidation, Chemical oxygen demand (COD).

*Corresponding author :

Pavithra MP

e-mail : mailto:pavithra.mp@ reva.edu.in

\begin{abstract}
Leachate originating in landfills where municipal solid wastes are disposed is a wastewater with a complex composition that could have a high environmental impact.The study aims to treat the landfill Leachate by electrochemical oxidation process in order to render the Leachate reasonable for inland disposal. Electrochemical oxidation of organic compounds from Leachate is a compelling method of breaking down pollutants which are resistant to biological degradation. The electrodes used in the process are graphite and titanium electrodes. At optimum conditions, the percentage removal by Graphite electrodes areCOD, TDS, Ammonia and Chloride were $52 \%, 57 \%, 60 \%$ and $45 \%$ respectively. The percentage removal by Titanium electrodes are COD, TDS, Ammonia and Chloride were 68\%, 80\%, 65\% and $58 \%$ respectively.
\end{abstract}

\section{INTRODUCTION}

$\mathrm{L}$ iquids that collect in a landfill are called Leachate and must be safely removed from the site for treatment. And the major problems to be considered are the generation of Leachate from solid waste dumping sites, which affects the ground water aquifers. Leachate from municipal solid waste is a major source of organic waste. And when this reaches the ground water table, it imparts adverse effects on the water stream. Today ground water is the only water source in many areas in India as well as in many countries. The Leachate from the solid waste on the surface of the ground enters the soil and reaches the groundwater table, thereby affecting it and preventing it for further use [1-4].

Leachate is a major environmental problem affecting the surroundings of landfill sites of municipal solid waste. The Leachate if not properly disposed in the landfill (with liners) might enter the ground water-table and contaminate the water. The human population near the landfill, using the water for drinking and other activities were admitted with less health related issues and this lead to government to take initiative in setting an integrated solid waste management for fewer dumpsites. The Leachate which has high concentration of organics, which is very harmful for human and child life.

Electrochemical processes are electronic transferences between two compounds where these transferences take place between the substratum and the metallic electrodes, usually inert, by means of the electrical current. Generally, these techniques work under soft conditions (room temperature and atmospheric pressure) but their main advantage is that they do not need the 
addition of any chemical reagent.The traditional methods like physical, chemical and biological methods have proven to be inefficient and costly in treating leachate. Electrochemical treatment has been developed as an alternative of conventional water and wastewater treatment. It mainly consisted of cathode, anode and power supply. Electrochemical reaction mainly occurs on electrode surface so increasing electrode surface was considered for long time [5-8].

Two important features:

1. Conversion of non-biocompatible organics into biocompatible compounds

2. Oxidation of organics into carbon-dioxide and waterwaste water treatment method because it gives us several advantages over traditional methods.

\section{Mechanism:}

- It is a complex phenomenon involving coupling of electron transfer reactions

- Two steps occur at anode-

1. In direct electrolysis, oxidation occurs at the electrode surface. The factors affecting are electrode activity, pollutants diffusion rate and current density.

2. In indirect electrolysis, oxidation occurs via surface mediator on anodic surface, where they are generated continuously. The factors affecting are temperature, $\mathrm{pH}$ and diffusion rate.

In indirect electro-oxidation, chloride salts of sodium or potassium are added to increase the conductivity.

The reactions of anodic oxidation:

$2 \mathrm{Cl}^{-} \rightarrow \mathrm{Cl}_{2}+2 \mathrm{e}^{-}$

The liberated chlorine forms hypochlorous acid:

$$
\mathrm{Cl}^{2}+\mathrm{H} 2 \mathrm{O} \rightarrow \mathrm{H}^{\mathrm{Cl}}+\mathrm{HOCl}
$$

and further dissociated to give hypochlorite ion

$$
\mathrm{HOCl} \rightarrow \mathrm{H}^{+}+\mathrm{Ocl}^{-}
$$

The generated hypochlorite ions act as main oxidizing agent in the pollutant degradation. In electrochemical oxidation process, the organic and toxic pollutants present in wastewater such as dye usually destroyed by either direct or indirect oxidation process.

The energy supplied to an electrochemical reactor plays an important role. The following steps occur when the energy is supplied to an electrode:

- The electro active particle is transferred to the electrode surface from the bulk solution.

- The electro active particle is adsorbed on to the surface of the electrode.

- Electron transfer occurs between the bulk and the electrode.

- The reacted particle is either transported to the bulk solution or deposited at the electrode surface.

\section{OBJECTIVE OF STUDY}

The objectives of the study are as follows:

- To characterize the leachate from a solid waste dumpsites.

- To study the effect of electrochemical oxidation on landfill leachate in order to render the leachate suitable for inland disposal, and also to study the effect of the operating parameters such as reaction time and current density by using Graphite electrode and Titanium electrode.

- To compare the relative efficiency by Graphite and Titanium electrodes in electrochemical oxidation of Leachate.

\section{MATERIALS AND METHODS}

\subsection{Sample Collection}

The landfill is situated at survey no.108, at Mavallipura village, Hesaragata zone, Bengaluru 
North, Karnataka state. This site has been used as processing for the municipal solid waste generated from the Bangalore city.

\subsection{Electrodes}

Graphite and Titanium electrode are selected as anode and cathode materials based on their properties like high electrical conductivity and low cost. Before each run electrode were washed with distilled water, dried, cooled and weighed.

\subsection{Experimental setup}

The reactor setup consists of a magnetic stirrer, DC regulator, a glass beaker of capacity of $500 \mathrm{ml}$, Graphite and Titanium as electrodes. The raw sample taken was $400 \mathrm{ml}$ and the electrodes were placed parallel to each other having an interelectrode gap of $2 \mathrm{~cm}$. The dimensions of the electrode were 50x50x4mm.

Landfill leachate is prepared by using distilled water to the $1 \%$ concentration i.e. $4 \mathrm{ml}$. Prepared leachate is transferred into electro chemical cell. For every 10 minutes, $5 \mathrm{ml}$ of samples were drawn and analysed for COD, TDS, Ammonia and chloride.

Table-1: Leachate characteristics

\begin{tabular}{|l|l|c|c|}
\hline $\begin{array}{c}\text { Sl. } \\
\text { No }\end{array}$ & \multicolumn{1}{|c|}{ Constituents } & Sample & $\begin{array}{c}\text { Disposal Standard } \\
\text { value (Inland } \\
\text { Surface Water) }\end{array}$ \\
\hline 1. & $\mathrm{pH}$ & 7.15 & 5.5 to 9.0 \\
\hline 2. & Conductivity $(\mu \mathrm{S} / \mathrm{cm})$ & 7530 & 5000 \\
\hline 3. & Ammonia $(\mathrm{mg} / \mathrm{L})$ & 93 & 50 \\
\hline 4. & TSS $(\mathrm{mg} / \mathrm{L})$ & 340 & 100 \\
\hline 5. & TDS $(\mathrm{mg} / \mathrm{L})$ & 9080 & 2100 \\
\hline 6. & COD $(\mathrm{mg} / \mathrm{L})$ & 520 & 250 \\
\hline 7. & Chloride $(\mathrm{mg} / \mathrm{L})$ & 1677 & 1000 \\
\hline 8. & Sulphate $(\mathrm{mg} / \mathrm{L})$ & 107 & - \\
\hline 9. & $\begin{array}{l}\text { BOD } 3 \text { days at } 270 \mathrm{C} \\
(\mathrm{mg} / \mathrm{L})\end{array}$ & 145 & 30 \\
\hline 10. & BOD/COD ratio & 0.25 & - \\
\hline 11. & Nitrate $(\mathrm{mg} / \mathrm{L})$ & 64 & - \\
\hline
\end{tabular}

\subsection{Analysis}

The leachate sample was characterized by almost neutral $\mathrm{pH}$, high conductivity suitable forelectrolysis, with a high TDS of $9080 \mathrm{mg} / \mathrm{L}$. the sample also contained significant amount of chloride thatcontributed to conductivity. The leachate has high value of ammonical nitrogen (93 $\mathrm{mg} / \mathrm{L})$ and chloride (1677 $\mathrm{mg} / \mathrm{L})$; in electrochemical oxidation (indirect oxidation) the ammonical nitrogen removal was studied (Table -1). The electrochemical oxidation method is the best option available for treating the ammonical nitrogen.

The Leachate was subjected to electrolysis until the paleyellow colour of the leachate is faded to give a clear solution. During the electrochemical

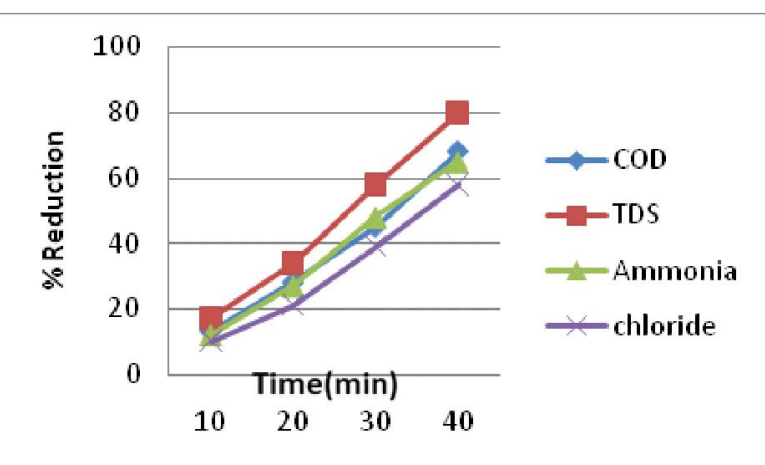

Fig.1: Effect of Reaction time with Titanium Electrode

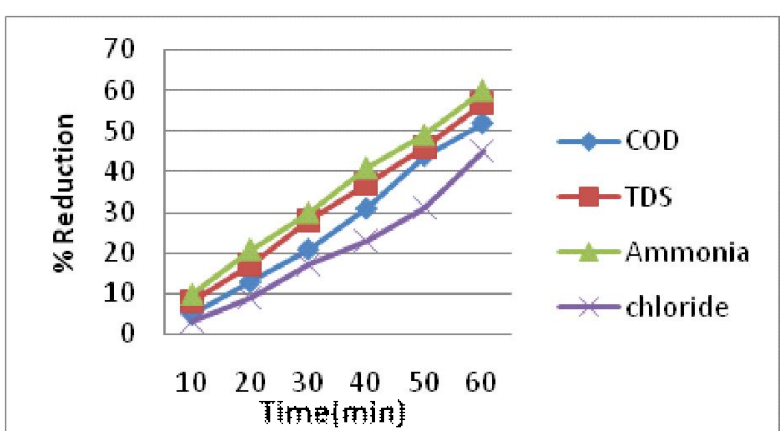

Fig.2: Effect of Reaction time with Graphite Electrode

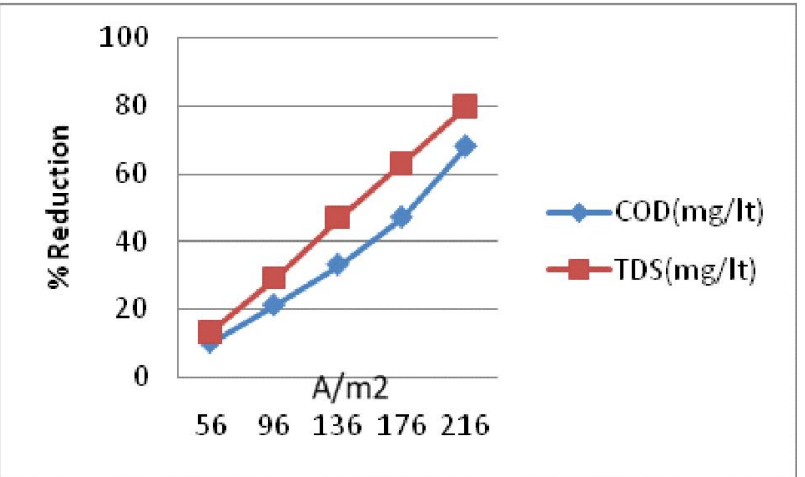

Fig.3: Effect of current density with Titanium Electrode 


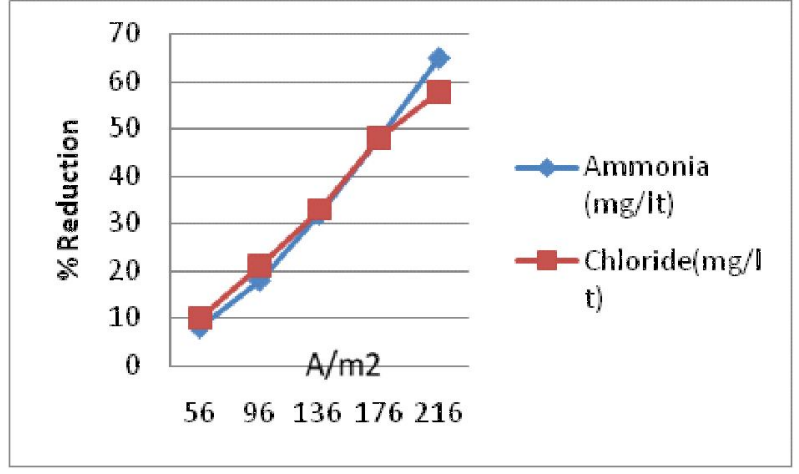

Fig.4: Effect of current density with Titanium Electrode

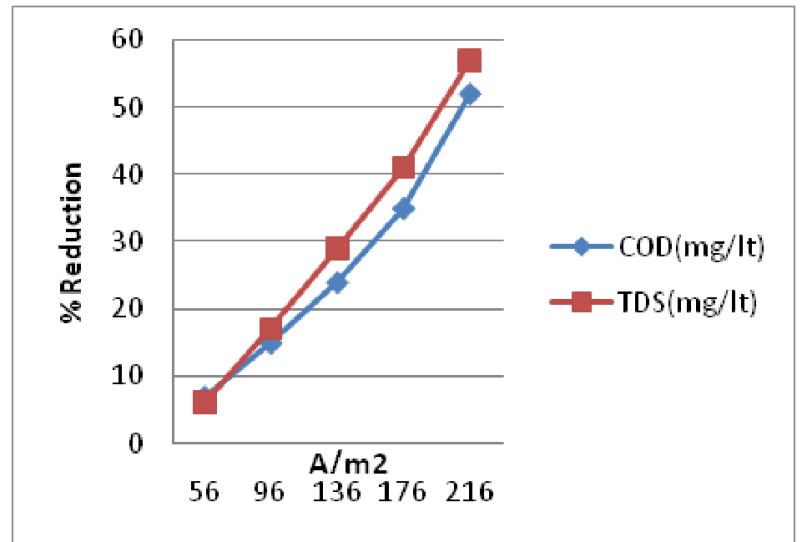

Fig.5: Effect of current density with Graphite Electrode

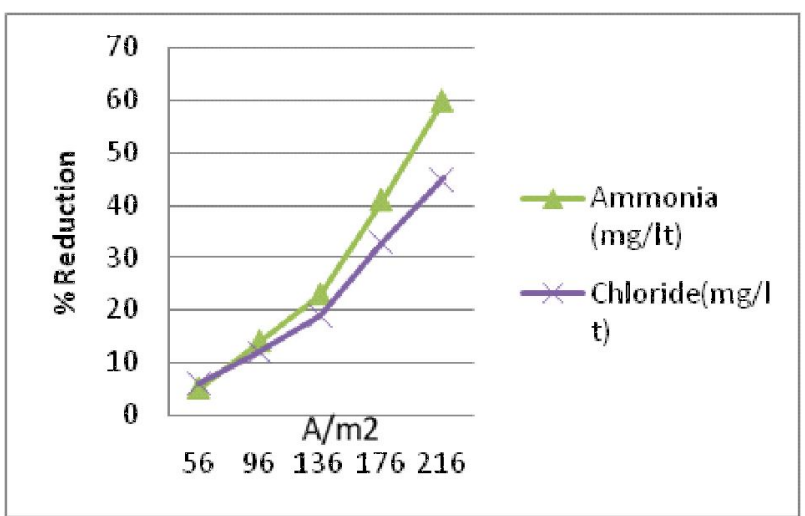

Fig.6: Effect of current density with Graphite Electrode

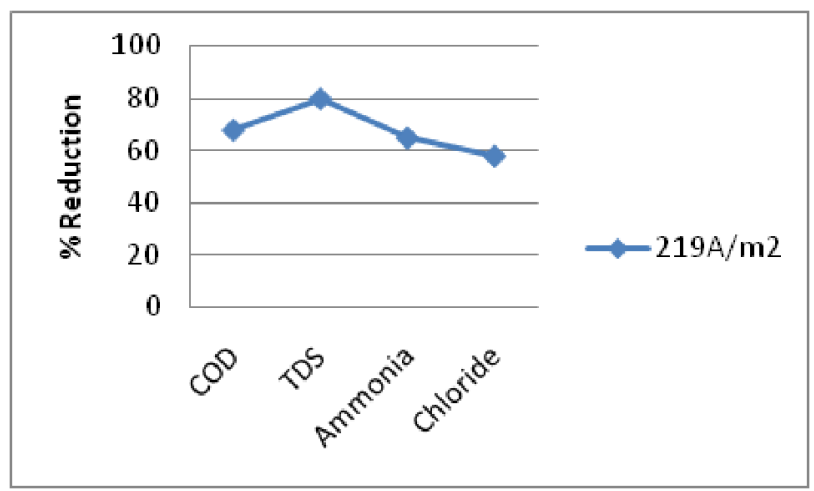

Fig.7: Removal of different parameters at 219A/m2 with Titanium Electrode

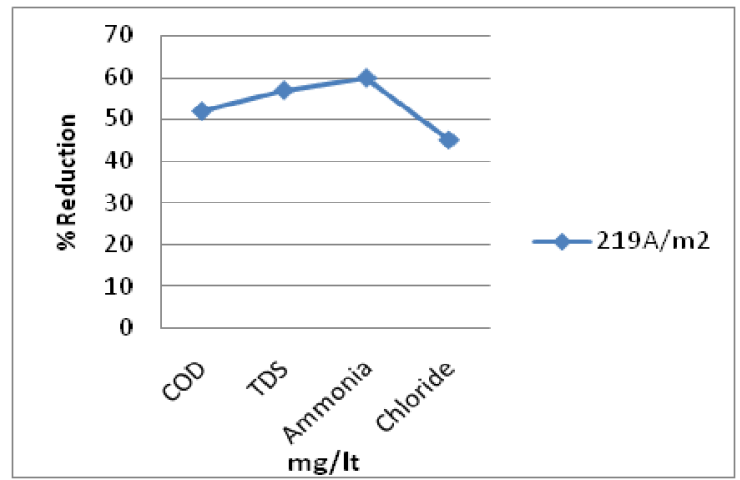

Fig.8: Removal of different parameters at 219A/m2 with Graphite Electrode

oxidation, the influence of reaction time and applied current was studied.

\section{DISCUSSION}

The influence of the Graphite and Titanium electrodes on the removal of ammonical nitrogen and chloride removal was studied.

The study with Titanium material was completed and it was observed that at 40 minutes reaction time, $216 \mathrm{~A} / \mathrm{m}^{2}$ current density, (Fig.1).

The study with Graphite material was completed and it was observed that at 60 minutes reaction time, $216 \mathrm{~A} / \mathrm{m}^{2}$ current density, (Fig.2).

The removal of TDS, Chloride, COD and Ammonia obtained a maximum percentage removal when Titanium electrode was employed (Fig. 3). The operating parameters obtained optimum conditions at the earliest and very efficient. The optimum conditions were 40 minutes Reaction time, Current Density 216 A/ $\mathrm{m} 2$, the percentage removal of COD, TDS, Ammonia and Chloride were 68\%, 80\%, 65\% and $58 \%$ respectively (Fig. 4-7).

The removal of TDS, Chloride, COD and Ammonia obtained a percentage removal when Graphite electrodewas employed. The operating parameters obtained optimum conditions at the earliest and very efficient. The optimum conditions were 60 minutes Reaction time, Current Density $216 \mathrm{~A} / \mathrm{m} 2$, the percentage removal of COD, TDS, 
Ammonia and Chloride were 52\%, 57\%, 60\% and $45 \%$ respectively (Fig. 8 ).

\section{CONCLUSION}

Electrochemical treatment provides a high precent removal of chlorides, TDS, Ammonia. The dissolved solids were removed to the extent of $80 \%$ from its initial concentration of $9080 \mathrm{mg} / \mathrm{L}$ by employing Titanium material with optimum Current density of $216 \mathrm{~A} / \mathrm{dm} 2$, with 40 minutes Reaction time.

The COD were removed to the extent of $68 \%$ from its initial concentration of $520 \mathrm{mg} / \mathrm{L}$ by employing Titanium material with optimum Current density of $216 \mathrm{~A} / \mathrm{m} 2$, with 40 minutes Reaction time.

The Chloride and ammonia were removed to the extent of $58 \%$ and $65 \%$ from its initial concentration of $1677 \mathrm{mg} / \mathrm{L}$ and $93 \mathrm{mg} / \mathrm{L}$ respectively, by employing graphite material with optimum Current density of $216 \mathrm{~A} / \mathrm{m} 2$, with 60 minutes Reaction time.

Similarly, the removal of TDS, Chloride, COD and Ammonia obtained a percentage removal when Graphite was employed. The percentage removal of COD, TDS, Ammonia and Chloride were $52 \%, 57 \%, 60 \%$ and $45 \%$ respectively.

Hence it is concluded from the above study is that Titanium is the better electrodes than graphite in the aspect of treating the pollutant efficiently, but in-case of cost aspect the Titanium is costlier than graphite, which is cheap and easily available.

It can be concluded that electrochemical oxidation method is an advanced technology which is able to treat landfill leachate having high
COD and colour efficiently before it is treated further or discharged into the water bodies.

\section{REFERENCES}

[1] Amokrane. A., Comel. C and Veron. J., 1997. Landfill Leachate pre-treatment by coagulation flocculation, Water res, 31, pp 2775-2782.

[2] APHA., 2005. Standard methods for the examination of water and waste water. 21st Edition, American Public health Association, Washington D.C.

[3] APHA-AWWA-WPCF., 1998.Standard methods for the examination of water and waste water, 20th Edition, American Public Health Association, Washington D.C.

[4] Aziz. H. A., Alias. S., Adlan. M. N., Asaari. F. A. H. and Zahari. M. S. M., 2007. Colour removal from landfill Leachate by coagulation and flocculation process, Bio resource Tech, 98, 218-220.

[5] BhaskarRaju. G., ThalamadaiKaruppiah. M., Latha. S. S., LathaPriya. D., Parvathy and Prabhakar. S., 2009, Electrochemical pretreatment of textile effluents and effect of electrode materials on the removal of organics, Science Direct, Desalination, $249,167-174$

[6] Nisha Priya.M., Esakku. S and K. Palanivelu., 2005 Electrochemical Treatment of Landfill Leachate, Centre for Environmental Studies, Anna University, Indian Chemical Engineer, pp 272-276

[7] Rajkumar. D., Palanivelu. Kand N. Balasubramanian., 2004. Combined electrochemical degradation and activated carbon adsorption treatments for wastewater containing mixed phenolic compounds, J. Environ. Eng. Science, 4, 1-9

[8] Rohit Mishra., NitinGedam., SujataWaghmare., SmitaMasid and Nageswara Rao Neti., 2009, Landfill Leachate Treatment by the Combination of Physical-Chemical and Electrochemical Methods, Journal of Environ Science \& Engine., 51(4), pp 315320. 
